\title{
The beneficial effect of long-term supplementation of vitamin $C$ on renal mitochondrial disturbances in streptozotocin-induced diabetic rats
}

\author{
Mariem Yusuksawad ${ }^{\mathrm{a}}$, Narongsak Chaiyabutr ${ }^{\mathrm{b}}$ \\ ${ }^{a}$ Department of Physiology, Faculty of Medicine; ${ }^{\mathrm{b}}$ Department of Physiology, Faculty of Veterinary \\ Sciences, Chulalongkorn University, Bangkok 10330, Thailand
}

\begin{abstract}
Background: Oxidative stress induces renal dysfunction in diabetes, in which renal mitochondrial disturbance was implicated. Vitamin C (VC) supplementation may ameliorate the renal dysfunction in diabetics. However, it is not clear whether VC supplementation is effective for renal mitochondrial disturbances in diabetes.

Objective: Investigate whether long-term continuous VC supplementation could ameliorate the renal mitochondrial disturbances in streptozotocin (STZ)-induced diabetic rats.

Methods: Thirty-five male Sprague-Dawley rats were used, and diabetes was induced by an injection of STZ. The rats were divided into three groups: control rats (CON), STZ-induced diabetic rats (STZ), and diabetic rats supplemented by vitamin C (STZ-VC). The CON and STZ rats were given tap water, while STZ-VC rats received VC $(1 \mathrm{~g} / \mathrm{L})$ every day for eight, 24 and 52 weeks. The kidney was isolated and homogenized. Oxygen comsumption $\left(\mathrm{Vo}_{2}\right)$ was measured in mitochondria homogenate using an oxygen consumption monitor. Based on $\mathrm{Vo}_{2}$ tracings, the respiration control index $(\mathrm{RCI})$ and $\mathrm{P} / \mathrm{O}$ ratio $(=\mathrm{ADP} / \mathrm{O}$ ratio) were measured at week 8, 24 and 52.

Results: At week eight, using either glutamate plus malate (for site I) or succinate (for site II) as substrates, both $\mathrm{RCI}$ and $\mathrm{P} / \mathrm{O}$ ratio were not significantly different among three groups. The $\mathrm{P} / \mathrm{O}$ ratio in STZ and STZ-VC rats increased from eight to 52 weeks after VC supplementation. At week 24, the $\mathrm{P} / \mathrm{O}$ ratio at site II was normalized in STZ-VC rat. The increased P/O ratio (only site I) and the increased RCI (only site II) of STZ-VC rats were slower than those of STZ rats.

Conclusion: Short-term VC supplementation might not influence the renal mitochondrial activity. The long-term VC supplementation could ameliorate the mitochondrial disturbances induced in STZ-induced diabetic rats.
\end{abstract}

Keywords: Diabetic rats, kidney, mitochondrial activity, mitochondrial $\mathrm{Vo}_{2}, \mathrm{STZ}$, vitamin C

In diabetes, oxidative stress induces mitochondrial disturbance in the kidney. The oxidative stress-induced renal mitochondrial disturbances have been demonstrated in diabetic rats [1-3]. During the progression of diabetes, the activities of mitochondrial enzymes are changed. In fact, animal studies using kidney of streptozotocin (STZ)-induced diabetic rats reported that ATPase activity increased at four weeks of diabetic stage, but decreased at 24 weeks $[4,5]$. NADH/cytochrome $\mathrm{C}$ oxidoreductase activity decreased at week 16 , while the activity of

Correspondence to: M. Yusuksawad, Ph.D, Department of Physiology, Faculty of Medicine, Chulalongkorn University, Bangkok 10330, Thailand. E-mail: myusuksawad@hotmail.com $\beta$-hydroxybutyrate dehydrogenase involving in NADH production increased at week 24 [6]. In addition, a decrease in oxidative phosphorylation and mitochodrial complex III activity has been noted in chronic diabetic rat kidney [3].

Vitamin C (VC) has an effect on mitochondrial activity [7]. VC supplementation may prevent mitochondrial damage and dysfunction in hypoxic rat $[8,9]$. In diabetic rats, $\mathrm{VC}$ levels decrease in plasma and organs $[10,11]$. Deficiency of VC leads to the enhancement of oxidative stress, which might cause renal mitochondrial dysfunction in diabetes.

In previous studies [12, 13], we showed that $\mathrm{VC}$ supplementation could ameliorate the renal dysfunction in STZ-induced diabetic rats. The 
supplemented VC might be effective for protection of damage in the mitochondria that is the major site of oxidative process in the cell. However, it is still unclear how the VC interacts with mitochondrial enzyme. In this study, we investigated the effect of long-term continuous VC supplementation on the renal mitochondrial activity in STZ-induced diabetic rats.

\section{Materials and methods}

This study was approved by the Ethics Committee of the Faculty of Pharmacy, Chulalongkorn University. The experiment was conducted according to the guideline for experimental animals by The National Research Council of Thailand.

\section{Animal model}

Thirty-five male Sprague-Dawley rats, weighing 180-220 gram, were used for this study. Diabetes was induced by an intravenous injection of STZ $(55 \mathrm{mg} / \mathrm{kg}$ body wt) as previously described $[12,13]$. The rats were divided into three groups, control rats $(\mathrm{CON})$ $(\mathrm{n}=8), \mathrm{STZ}$-induced diabetic rats $(\mathrm{STZ})(\mathrm{n}=12)$, and diabetic rats supplemented by vitamin C (STZ-VC) $(n=15)$. The CON rats were injected with the vehicle of citrate buffer. The CON and STZ rats were given tap water, while the STZ-VC rats received VC $(1 \mathrm{~g} / \mathrm{L})$ ad libitum every day for 8, 24 and 52 weeks.

\section{Measurement of mitochondrial activity}

At the end of the experimental periods, blood was withdrawn from the rats that were fasted for 9-10 hours. The blood glucose concentrations were measured using a glucometer (Accu-Chek Advantage, Roche Diagnostics, Mannheim, Germany).

Then, the rats were anesthetized with pentobarbital sodium $(50 \mathrm{mg} / \mathrm{kg} \mathrm{BW}$ ip). The kidney was isolated in ice-cold homogenizing buffer and homogenized using a motor-driven tightly fitting glass/ Teflon Potter-Elvehjem homogenizer (Bellco Glass, Vineland, USA). The renal mitochondria were collected according to our previously-described procedure $[14,15]$. The total protein in mitochondrial homogenate was determined using Lowry's method [16].

The mitochondrial homogenate was put into a close chamber with Clark-type electrode, in which mitochondrial buffer was contained and continuously stirred with a magnetic stirring bar at $25^{\circ} \mathrm{C}$. Mitochondrial oxygen consumption $\left(\mathrm{Vo}_{2}\right)$ was measured using an oxygen consumption monitor (YSI
Model 5300, Biological Oxygen Monitor, Scientific Division, Yellow Springs Instrument Co, Ohio, USA). The $\mathrm{Vo}_{2}$-tracing was recorded using Flatbed Recorder (Dual Channel Model BD112, Kipp \& Zonen, Delft, Holland).

To examine the mitochondrial activity, we used different substrates as follows: glutamate plus malate as substrate for glutamate dehydrogenase and malate dehydrogenase in the mitochondrial activity at site I, and succinate as substrate for succinate dehydrogenase at site II. The dynamical process of respiration is composed of four stages [16]. By stimulating the phosphorylation with ADP, we determined $\mathrm{Vo}_{2}$ levels at resting and activating stage.

The mitochondrial activity was expressed in terms of two parameters, RCI (respiration control index) and $\mathrm{P} / \mathrm{O}$ ratio (amount of ADP added to the amount of consumed oxygen).

The $\mathrm{RCI}$ and $\mathrm{P} / \mathrm{O}$ ratio were calculated based on the $\mathrm{Vo}_{2}$-tracings and the added amount of ADP (600 nmole for site I or 300 nmole for site II) as follows (see Figure. 1):

$\mathrm{RCI}=\mathrm{Vo}_{2}$ at activating state $/ \mathrm{Vo}_{2}$ at resting state

$\mathrm{P} / \mathrm{O}$ ratio $=$ nmole of $\mathrm{ADP}$

Total oxygen consumption at activating state

$\mathrm{RCI}$ indicates the tightness of the coupling between respiration and phosphorylation, and $\mathrm{P} / \mathrm{O}$ ratio indicates the oxidative phosphorylation performance of the mitochondria.

\section{Statistical analysis}

The data were expressed as mean \pm standard deviation (SD). The statistical comparisons among groups were analyzed using ANOVA and least significant difference test as the post hoc test. Unpaired t-test was used for comparisons between periods. A p-value of less than 0.05 was considered significantly different.

\section{Results \\ Blood glucose concentrations}

The blood glucose concentrations of STZ and STZ-VC was four times significantly $(p<0.001)$ higher than those of the control rats. Twenty-four weeks after VC supplementation, the blood glucose concentration of STZ-VC decreased by $9 \%$ from that of STZ (not significantly different). 


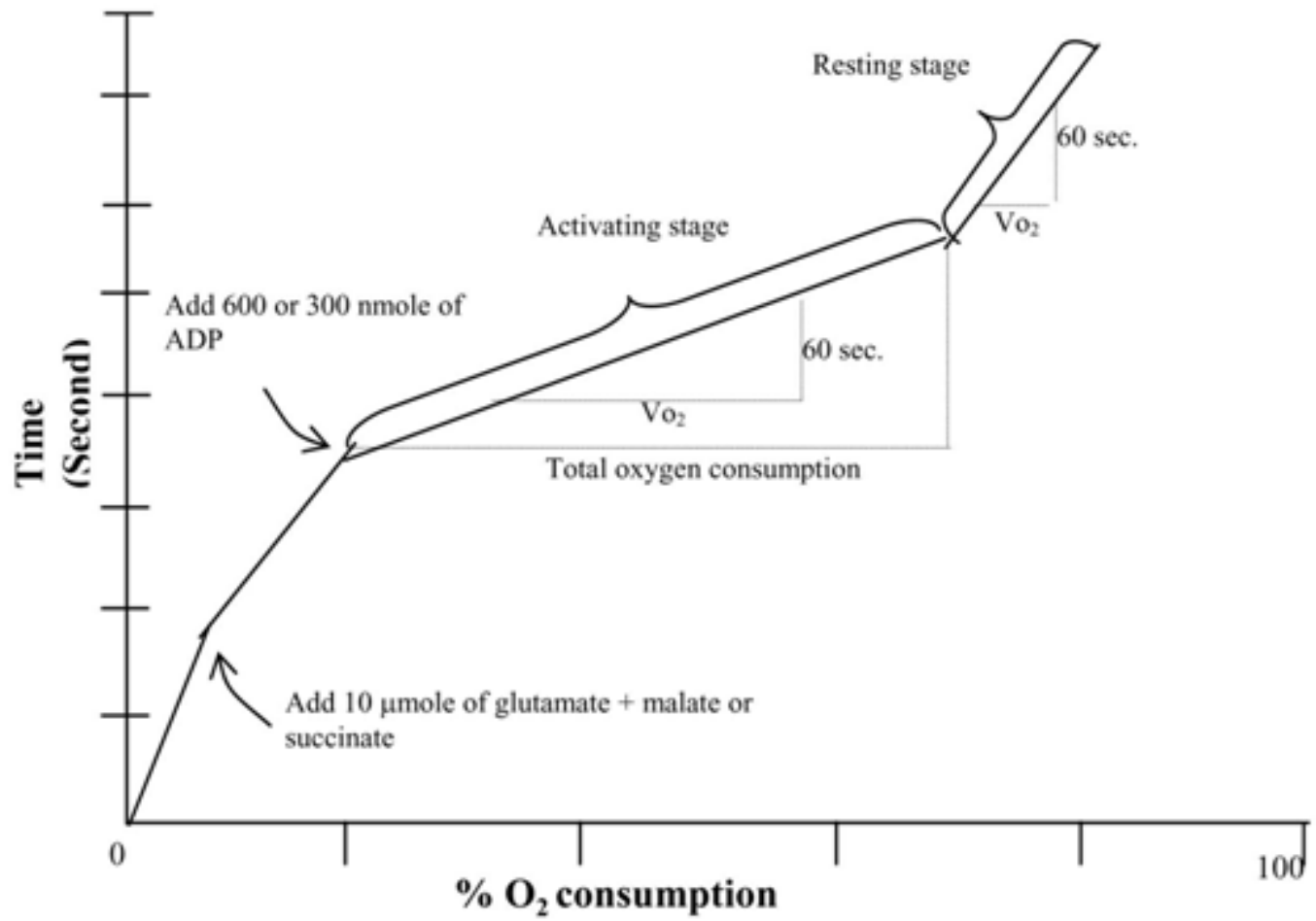

Figure. 1 Mitochondrial respiration tracing showing the oxygen consumption at resting and activating stage.

\section{Renal mitochondrial activity}

Table 1. Changes in $\mathrm{V}_{\mathrm{O}}$, $\mathrm{RCI}$ and $\mathrm{P} / \mathrm{O}$ ratio in the renal mitochondria activities site $\mathrm{I}$ and II in the diabetic rats with or without VC supplementation1.

\begin{tabular}{|c|c|c|c|c|c|}
\hline Renal mitochondrial activities & Site & $\begin{array}{l}\text { CON } \\
(n=4)\end{array}$ & $\begin{array}{l}\text { STZ } \\
(n=4)\end{array}$ & $\begin{array}{l}\text { STZ-VC } \\
(n=5)\end{array}$ & $\mathbf{P}-\mathbf{v}$ \\
\hline \multicolumn{6}{|l|}{ Week 8} \\
\hline VO2 at resting state & I & $10.4+2.0$ & $9.5 \pm 4.5$ & $9.0 \pm 3.5$ & $\mathrm{~ns}$ \\
\hline (ng atom $\mathrm{O}_{2} / \mathrm{min} / \mathrm{mg}$ protein) & II & $26.2 \pm 5.2$ & $27.6 \pm 7.0$ & $30.0 \pm 7.4$ & $\mathrm{~ns}$ \\
\hline VO2 at activating state & I & $76.6 \pm 15.1$ & $66.3 \pm 19.8$ & $54.6 \pm 17.4$ & $\mathrm{~ns}$ \\
\hline (ng atom $\mathrm{O}_{2} / \mathrm{min} / \mathrm{mg}$ protein) & II & $120.0 \pm 14.8$ & $122.5 \pm 51.3$ & $125.4 \pm 41.3$ & ns \\
\hline \multirow[t]{2}{*}{ RCI } & I & $7.5 \pm 1.9$ & $6.3 \pm 1.7$ & $6.3 \pm 1.3$ & $\mathrm{~ns}$ \\
\hline & II & $4.7 \pm 0.8$ & $4.5 \pm 0.9$ & $4.6 \pm 1.4$ & $\mathrm{~ns}$ \\
\hline $\mathbf{P} / \mathbf{O}$ & I & $1.7 \pm 0.4$ & $1.9 \pm 0.4$ & $2.0 \pm 0.2$ & $\mathrm{~ns}$ \\
\hline (nmol/ng atom $\mathrm{O}_{2} / \mathrm{mg}$ protein) & II & $1.6 \pm 0.5$ & $1.3 \pm 0.2$ & $1.8 \pm 0.6$ & $\mathrm{~ns}$ \\
\hline
\end{tabular}

Week 24

$\begin{array}{llllll}\text { VO2 at resting state } & \text { I } & 7.4 \pm 0.9 & 10.4 \pm 1.6^{\mathrm{a}} & 11.3 \pm 1.1^{\mathrm{a}} & \mathrm{p}<0.05 \\ \text { (ng atom } \mathbf{O}_{2} / \mathbf{m i n} / \mathbf{m g} \text { protein) } & \text { II } & 19.9 \pm 4.2 & 25.8 \pm 4.7 & 28.1 \pm 1.6_{\mathrm{a}} & \mathrm{p}<0.05 \\ \text { VO2 at activating state } & \text { I } & 43.3 \pm 5.1 & 62.4 \pm 12.8^{\mathrm{a}} & 62.6 \pm 8.3^{\mathrm{a}} & \mathrm{p}<0.05 \\ \text { (ng atom } \mathbf{O}_{2} / \mathbf{m i n} / \mathbf{m g} \text { protein) } & \text { II } & 100.2 \pm 15.7 & 127.4 \pm 25.3 & 125.0 \pm 10.1 & \mathrm{p}<0.05 \\ \text { RCI } & \text { I } & 5.8 \pm 0.4 & 6.0 \pm 0.4 & 5.5 \pm 0.4 & \mathrm{~ns} \\ & \text { II } & 5.1 \pm 0.9 & 5.0 \pm 0.8 & 4.5 \pm 0.6 & \mathrm{~ns} \\ \mathbf{P} / \mathbf{O} & \text { I } & 1.8 \pm 0.5 & 2.2 \pm 0.5 & 2.0 \pm 0.3 & \mathrm{~ns} \\ \text { (nmol/ng atom } \mathbf{O}_{2} / \text { mg protein) } & \text { II } & 1.3 \pm 0.3 & 1.7 \pm 0.2^{\mathrm{a}} & 1.5 \pm 0.2 & \mathrm{p}<0.05\end{array}$

Data are expressed as mean+SD. ${ }^{a}$ compared with $\mathrm{CON}, \mathrm{ns}=$ not significantly different compared with CON and STZ in the same row $(\mathrm{p}<0.05)$. 
Apparently, the $\mathrm{Vo}_{2}$ level of renal mitochondrial respiration at the activating state significantly increased compared with that at the resting stage. The increasing rates at week 8 were approximately 7 times and 5 times at site I and II, respectively. At week 8, compared with CON rats, the $\mathrm{Vo}_{2}$ was $13 \%$ and $29 \%$ lower in STZ and STZ-VC rats, respectively. At week 24 , the $\mathrm{Vo}_{2}$ of STZ and STZ-VC were higher $(\mathrm{p}<0.05)$ than those of $\mathrm{CON}$ in both resting stage and activating stage ( $40 \%$ and $50 \%$, respectively). These results were different from week 8. RCI (both site I and II) was not different among groups. Interestingly, STZ-VC had a decrease in $\mathrm{P} / \mathrm{O}$ ratio toward the control level.

\section{Changes of renal mitochondrial activity}

[A]
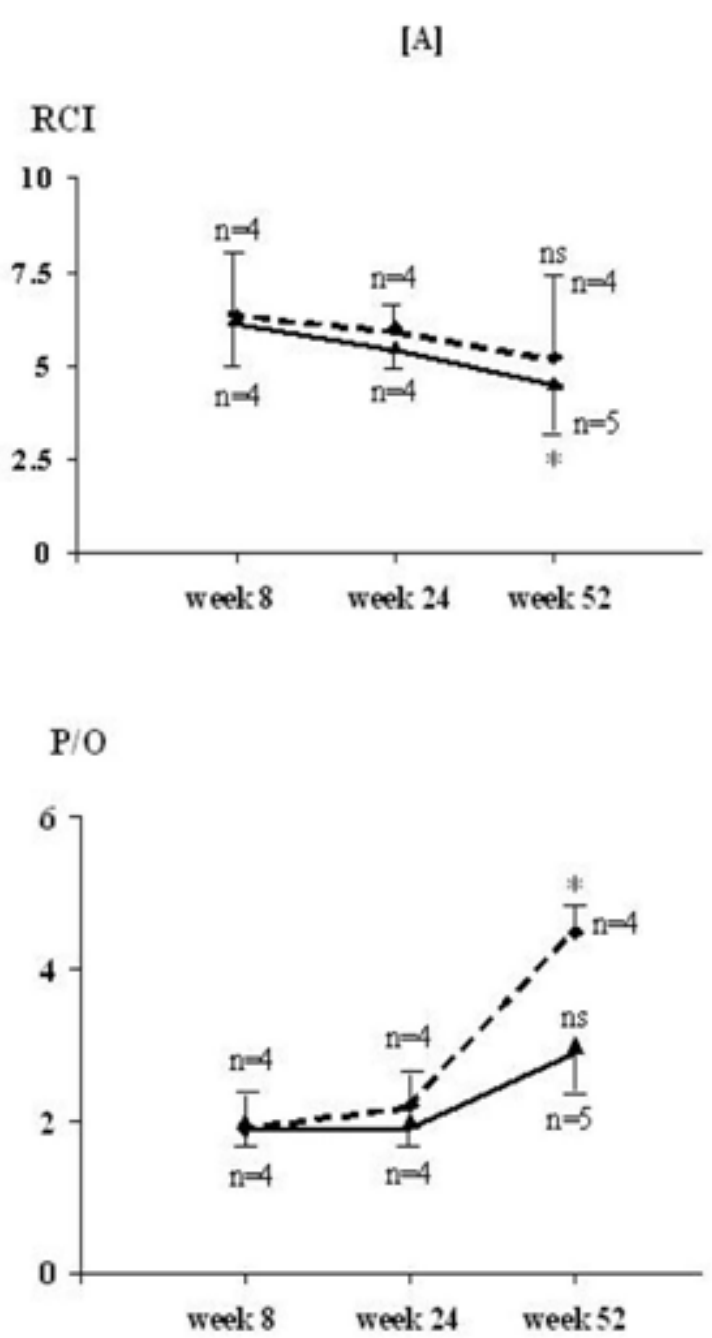

Figure 2 shows profile changes of the renal mitochondrial activities of STZ and STZ-VC during 8, 24 and 52 weeks. In STZ and STZ-VC rats, RCI at site I decreased from week 8 to week 52 , and RCI level in STZ-VC rats became lower than that in STZ rats at week 52. The $\mathrm{P} / \mathrm{O}$ ratios in STZ and STZ-VC rats increased from week 8 to week 52 . The increased $\mathrm{P} / \mathrm{O}$ ratio was slower in STZ-VC and non-significantly different compared with those at week 8 and 24 . At site II, RCI of STZ increased from week 8 to week 52. Different from STZ, STZ-VC did not show markable change of RCI during the periods. $\mathrm{P} / \mathrm{O}$ ratio of STZ increased significantly from week 8 to week 52. Interestingly, $\mathrm{P} / \mathrm{O}$ ratio of STZ-VC decreased toward the control level at week 24 , but it turned to increase after week 24.
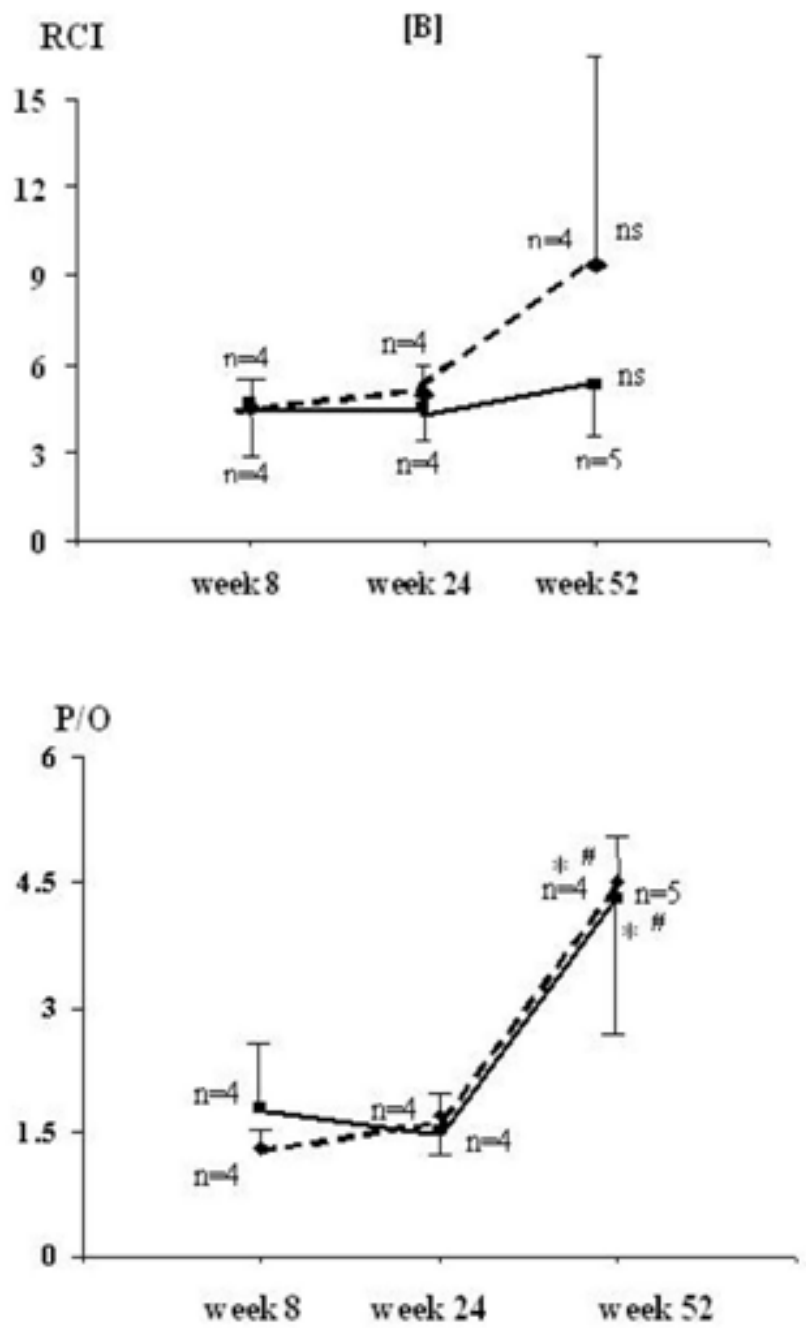

Figure. 2 Changes of RCI and P/O ratio in STZ and STZ-VC rats 8, 24 and 52 weeks after VC supplementation at site I (A) and site II (B). * ${ }^{*}$ compared with week $8(\mathrm{p}<0.05)$, ${ }^{*}$ compared with week 24 , ${ }^{\text {ns }}$ not significantly different among periods. STZ, — STZ-VC. 


\section{Discussion}

The present study was aimed to investigate whether VC supplementation could ameliorate the renal mitochondrial dysfunction in STZ-induced diabetic rats. In the present experiment, eight weeks after $\mathrm{VC}$ supplementation, $\mathrm{RCI}$, and $\mathrm{P} / \mathrm{O}$ ratio reflecting mitochondrial activities of STZ and STZ$\mathrm{VC}$ were not markedly changed both site I and site II. RCI of the diabetic rats slightly decreased from $\mathrm{CON}$ rats indicating a decrease in glutamate and malate dehydrogenase activities in the kidney mitochondria, while no alteration of $\mathrm{P} / \mathrm{O}$ ratio was apparent. This indicates that short-term (eight weeks) of VC supplementation might be not effective for the renal mitochondrial disturbances induced in diabetes.

More long-term VC supplementation induced some effect on mitochondrial activities in diabetic rats. At week 24, the $\mathrm{Vo}_{2}$ at site I and site II were higher than those of $\mathrm{CON}$ in resting and activating states, indicating increases in the activities glutamate, malate and succinate dehydrogenase in the diabetic rats, as reported previously [4]. However, these $\mathrm{Vo}_{2}$ increases do not result in decrease in $\mathrm{P} / \mathrm{O}$ ratios at site I because the increased amount of consumed $\mathrm{O}_{2}$ is utilized for the substrate oxidation. Since electrochemical gradient of $\mathrm{H}^{+}$between mitochondrial matrix and intermembrane space is essential for maintenance of the oxidative phosphorylation of ADP, the increase in the oxygen consumption at activating state might be mainly utilized for the substrate oxidation to keep the proton motive force but partially for ADP phosphorylation in diabetic rats. The increase in the utilization of consumed $\mathrm{O}_{2}$ for the substrate oxidation in diabetes may be apparently supported by the rapid oxygen consumption at the resting state. Since oxidative phosphorylation of ADP needs high gradient of proton, the large amount of oxygen is consumed to generate enough potential for oxidative phosphorylation of ADP to ATP in diabetic renal mitochondria.

In the STZ-VC rats, the $\mathrm{P} / \mathrm{O}$ ratio was suppressed to elevate compared with STZ rats. In general, VC reacts directly with most oxidants [17], and enters mitochondria via facilitative glucose transporter 1 [18]. The electron in the inner-membrane of mitochondria may be scavenged by the accumulated $\mathrm{VC}$, which results in decrease in the amount of electron in the respiration chain. Accordingly, the oxidative phosphorylation is slowed down, so that the elevation in $\mathrm{P} / \mathrm{O}$ ratio is reduced. This tendency appeared markedly at site II (Table 1). P/O ratios in STZ-VC and STZ rats are non-significantly different, but the increased $\mathrm{P} / \mathrm{O}$ ratio in $\mathrm{STZ}-\mathrm{VC}$ rats is reduced toward the control level by VC supplementation for 24 weeks. Although the number of samples in the present study is small, the standard deviation of the statistical different is small as well (less than $50 \%$ of the mean value). We could obtain the accuracy for the in vitro study of the mitochondria activities as previous report [19]. The present results suggest that VC supplementation may have a beneficial effect on renal mitochondrial disturbances in diabetes. The amelioration of renal mitochondrial disturbances may be related with the improvement of endothelial dysfunction and renal dysfunction in diabetic rats treated VC as the previous study $[13,20]$. However, the beneficial effect on renal mitochondrial disturbance was not lasting after 52 weeks of VC supplementation (Figure. 2B).

In conclusion, mitochondrial disturbances in STZinduced diabetic rats occurred with the increased $\mathrm{P} /$ $O$ ratio, and possibly, loss of electrochemical gradient of proton between mitochondrial matrix and intermembrane space and increases in the involving enzyme activity, especially glutamate, malate and succinate dehydrogenase. The long-term continuous VC supplementation could retard the increased $\mathrm{P} / \mathrm{O}$ ratio and partially ameliorate the mitochondrial dysfunction in the streptozotocin-induced diabetic rats.

\section{Acknowledgements}

This study was supported by Thai Ministry of University Affairs (MUA-CU Thesis Grant) and Ratchadapiseksompoch Grant for young researchers from Chulalongkorn University. The authors have no confliction of interest to declare.

\section{References}

1. Jang YY, Song JH, Shin YK, Han ES, Lee CS. Protective effect of boldine on oxidative mitochondrial damage in streptozotocin-induced diabetic rats. Pharmacol Res. 2000; 42:361-71.

2. Rosca MG, Monnier VM, Szweda LI, Weiss MF. Alterations in renal mitochondrial respiration in response to the reactive oxoaldehyde methylglyoxal. Am J Physiol. Renal Physiol. 2002; 283: F52-9.

3. Rosca MG, Mustata TG, Kinter MT, Ozdemir AM, Kern TS, Szweda LI, Brownlee M, Monnier VM, et al. Glycation of mitochondrial proteins from diabetic rat kidney is associated with excess superoxide formation. Am J Physiol Renal Physiol. 2005; 289:F420-30. 
4. Katyare SS, Satav JG. Effect of streptozotocin-induced diabetes on oxidative energy metabolism in rat kidney mitochondria. A comparative study of early and late effects. Diabet Obes Metab. 2005; 7:555-62.

5. Stefek M, Tribulova N, Gajdosik A, Gajdosikova A. The pyridoindole antioxidant stobadine attenuates histochemical changes in kidney of streptozotocininduced diabetic rats. Acta Histochem. 2002; 104. 413-7.

6. de Cavanagh EMV, Ferder L, Toblli JE, Piotrkowski B, Stella I, Fraga CG, et al. Renal mitochondrial impairment is attenuated by AT1 blockade in experimental Type I diabetes. Am J Physiol Heart Circ Physiol 2008; 294 : H456-65.

7. Przedborski S, Jackson-Lewis V, Fahn S. Antiparkinsonian therapies and brain mitochondrial complex I activity. Mov Disord. 1995; 10:312-7.

8. Rosa EF, Ribeiro RF, Pereira FMT, Freym ller E, Aboulafia J, Nouailhetas VLAS. Vitamin C and E supplementation prevents mitochondrial damage of ileum myocytes caused by intense and exhaustive exercise training. J Appl Physiol. 2009; 107:1532-38.

9. Luo G, Xie ZZ, Liu FY, Zhang GB. Effects of vitamin C on myocardial mitochondrial function and ATP content in hypoxic rats (in Chinese). Zhongguo-Yao-Li-XueBao. 1998; 19:351-5.

10. Seghieri G, Martinoli L, Miceli M, Ciuti M, D’Alessandri $\mathrm{G}$, Gironi A, et al. Renal excretion of ascorbic acid in insulin dependent diabetes mellitus. Int J Vitam Nutr Res. 1994; 64:119-24.

11. Lindsay RM, Jamieson NS, Walker SA, McGuigan CC, Smith W, Baird JD. Tissue ascorbic acid and polyol pathway metabolism in experimental diabetes. Diabetologia. 1998; 41:516-23.

12. Yusuksawad MS, Chaiyabutr N. Changes in renal hemodynamics in streptozotocin-induced diabetic rats with L-ascorbic acid supplementation. Clin Hemorheol Microcirc. 2006; 27:67-76.

13. Yusuksawad MS, Thongruay S, Le Grand SM, Chaiyabutr N. Long-term effects of vitamin C supplementation on glomerular pathophysiological changes in streptozotocin-induced diabetic rats. Asian Biomed. 2007; 1:279-87.

14. Suanarunsawat T, Klongpanichapak S, Chaiyabutr, N. Role of nitric oxide in renal function in rats with short and prolonged periods of streptozotocin-induced diabetes. Diabetes Obes Metab. 1999; 1:339-46.

15. Estabrook RW. Mitochondrial respiratory control and the polarographic measurement of ADP:O ratios. In: Colowick SP, Kaplan NO, editors. Methods in Enzymology, Vol 10. New York:Academic Press; 1967, p. 41-7.

16. Lowry OH, Rosebrough JN, Farr AL, Randall RJ. Protein measurement with the Folin reagent. J Biol Chem. 1951; 193:265-75.

17. Halliwell B. Vitamin C: antioxidant or proxidant in vivo. Free Radic Res. 1996; 25:439-54.

18. Sagun KC, C rcamo JM, Golde DW. Vitamin C enters mitochondria via facilitative glucose transporter 1 (Glut1) and confers mitochondrial protection against oxidative injury. FASEB J. 2005; 19:1657-67.

19. Chaiyabutr N, Jakobsen PE. The influence of dietary iodine and environmental temperature on the activity of mitochondria in liver and kidney. J Anim Physiol Anim Nutr. 1978; 40:225-35.

20. Jariyapongskul A, Rungiaroen T, Kasetsuwa N, Patumraj S, Niimi H. Long-term effects of oral vitamin C supplementation on the endothelial dysfunction on the iris microvessels of diabetic rats. Microvas Res. 2007; 74:32-8. 